\title{
POLÍTICAS AMBIENTAIS: UMA POSSIBILIDADE DE CURRÍCULO
}

\author{
Jose Luis Abalos Junior ${ }^{1}$
}

Este relato é fruto de reflexões que tive na graduação em Ciências Sociais e no Mestrado Acadêmico em Antropologia Social (PPGAS/UFRGS) nos quais me deparei inúmeras vezes com a reflexão da questão das políticas que envolvem a temática ambiental. Entendendo estas experiências como significativas para o desenvolvimento dos estudos ambientais dentro de perspectivas antropológicas, faço uma síntese sobre os principais conceitos a serem tratados em propostas como a de um currículo de estudo. Entre estes conceitos se inserem o de responsabilidade social e ambiental entrando no debate da conferência da ONU sobre "o futuro que queremos". Riscos ambientais e contaminação também são categorias de importante discussão num programa desse tipo. O debate sobre políticas e democracia traz a tona a análise de políticas ambientais como a de Belo Monte. A contextualização de novos tipos de cidadania, como a ecológica, desperta atenção para novos conceitos como o de sustentabilidade e desenvolvimento sustentável. Esse modelo de trânsitos na política instiga novos debates como o de Conflitos e Justiça Ambientais. Assim como a política em transito adentra a discussão sobre o que são populações tradicionais. A Educação Ambiental aparece nesse sentido como uma dimensão político-pedagógica importante para o desenvolvimento de novos sujeitos capazes de pensar a "política do eu" e as "políticas da natureza". Por fim, faço uma breve reflexão sobre a produção de uma antropologia vitalista em Tim Ingold relacionando com o rompimento de uma disciplinaridade, empreitada importante ao dialogarmos sobre políticas ambientais.

\section{A Crise e o Risco como ferramentas para se discussão da responsabilidade social}

A reflexão sobre o conceito de responsabilidade pode ser um começo para começar-se a pensar um programa de políticas ambientais. A partir Hans Jonas em "O principio da responsabilidade" pode-se refletir sobre a ética da reciprocidade em relação ao meio-ambiente. A natureza não entra na ética do "dar, receber e retribuir". A preservação da natureza se dá pelo o que ela é e não por uma espécie de humanização. Logo a responsabilidade ambiental está baseada num dever (não direito) não recíproco.

\footnotetext{
${ }^{1}$ Universidade Federal do Rio Grande do Sul, Brasil.
} 
Distinguem-se assim dois princípios opostos: o da responsabilidade e o da reciprocidade. Feito isto, entre direitos e deveres só existe direitos para aqueles que, de fato, existem. As futuras gerações não são sujeitos de direitos. Porém nós que existimos hoje temos deveres representados em responsabilidades com o futuro da humanidade. $\mathrm{O}$ primeiro deste seria o de garantir a existência de um futuro estabelecido através da procriação. O segundo diz respeito a garantia de modos de existência melhores as futuras gerações. Além de garantir a existência é de responsabilidade da sociedade atual o modo de ser da futura humanidade. Como salienta Hans Jonas (2005):

Portanto, para nós, contemporâneos, em decorrência do direito daqueles que virão e cuja existência podemos desde já antecipar, existe um dever como agentes causais graças ao qual nós assumimos para com eles a responsabilidade. Por nossos atos cujas dimensões impliquem repercussões em longo prazo.

No que refere à categoria de riscos ambientais é interessante analisar esse conceito vindo ora por uma reflexão da Epidemiologia referente à saúde pessoal e social, ora por outra da Economia em que está ligado a um tipo de investimento sem reservas. Na perspectiva do risco como evento termo "ambiental" aparece relacionado à vulnerabilidade dos grupos de risco ambiental. Nesse sentido o espaço da radioatividade tem sido um locus privilegiado para a reflexão sobre a categoria de risco. No estudo sobre a construção social do risco Glaucia Oliveira da Silva o contexto da Usina de Angra I no Rio de Janeiro. E em "Corpos em perigo: uma análise sobre percepção de risco em caso de desastre radiológico" Telma Camargo da Silva se debruça sobre as percepções de um desastre radiológico (1987) com a cápsula de Césio-137 em Goiás. Seguindo a análise de crises e riscos ambientais outra análise é de políticas e democracia refletindo sobre casos específicos.

O livro "Conflitos Ambientais no Brasil" de Henri Acselrad pode ser uma boa ferramenta para este tipo de analise. Ao contextualizar os conflitos sociais e a mudança ambiental o autor traz um caso da Barragem do Tucuruí em que houve a construção de uma usina hidrelétrica na localidade. Tal empreendimento refletiu no deslocamento de cerca de 10 mil famílias. A ausência de uma política negociada com interlocutores socialmente legitimados constitui fator de acirramento da posição de antagonismo das populações locais em face do empreendimento. Todos os fatores exprimiam, em última instância, problemas relativos à reinserção ambiental das populações em suas dimensões físico-materiais e socioculturais. Esta experiência de construção da usina é, por um lado, 
representação do que um planejamento autoritário pode produzir como desestruturação sociocultural e evidenciação de dominação política, mas, ela permite, por outro lado, exercitar o entendimento da tão discutida questão ambiental como pertinente a um momento da luta social por apropriação territorial e por atribuição de sentidos, via de regras de diversos e, frequentemente, conflitais, a uma base material que se oferece como sustentação de projetos distintos de desenvolvimento. Assim é perceptível como as dimensões ambientais e fundiárias articulam-se de modo a construir uma pluralidade multiforme de conflitos sociais tendo o meio ambiente como objeto. Logo é a organização política desses grupos atingidos por tais políticas e as experiências criativas de suas lutas que fazem de sua resistência condição da construção de projetos de desenvolvimento menos danosos e mais democráticos.

\section{Dos conceitos às epistemologias: cidadania, meio ambiente e desenvolvimento sustentável}

Outro modulo para pensar esta disciplina é o de "epistemologias ambientais" relacionando-o com questões históricas em torna da cidadania e meio ambiente e com sustentabilidade ambiental. Uma obra significativa para começar essa discussão é "A formação do sujeito ecológico" de Isabel Carvalho. Nesse primeiro caso é interessante analisar o capítulo "A política em transito e os trânsitos na política" refletindo sobre esse nascimento de um novo sujeito que explica - através da reflexão sobre as trajetórias de sujeitos ecológicos - o que é ser ambientalista como um conceito plural: para além daquilo que é ambiental. Sendo assim, entender a capacidade que essa discussão tem de agregar outras discursões. Pensar em que sujeito ecológico é este que está a favor de um futuro comum, e que cidadania é essa que se expressa nos modos distintos de fazer - ligado a um permanente trânsito no discurso e na ação política. Contextualizando como esse discurso se dá no campo da política e como se dá à formação do campo ambiental, a autora coloca que isso gera/gerou um "trânsito na política" inserindo um debate sobre a atomização do sujeito e da ação nesse campo. Abordando que "a crise ecológica real não oferece em si nenhum substrato para uma orientação de política ecológica", reflete sobre conceitos como "ecofacismo" ligado a apropriação dos problemas ambientais e dos discursos ecológicos pelo capitalismo. Já em relação à entrada de "ideias verdes" no debate político nacional, elas estão marcadas 
pelo debate europeu sobre ecologia e pacifismo e a política inspirada na contracultura e na luta das minorias. Todos estes fatores geraram uma nova cultura política de caráter emancipatório associada a uma nova esquerda e á "política do eu". Sendo assim a autora reflete sobre quatro trajetórias diferentes e irredutíveis entre si abridoras de caminhos e inventoras de alternativas.

Nenhuma ideologia possui, em última instância mais valor ou lógica que uma pessoa que lhe empresta a virtude de sua própria ação: a política é feita de envolvimentos pessoais e não de idéias abstratas. (Carvalho, Isabel C. M.; 2008)

Em "Desenvolvimento sustentável: a história de um conceito" Gabriela Scotto, Isabel Carvalho e Leandro Guimarães refletem que para entender a ideia de desenvolvendo sustentável é necessário refletir sobre as origens históricas do próprio conceito de desenvolvimento nascido numa perspectiva ocidental do pós-guerra onde era necessário reconstruir as sociedades afetadas e estabelecer uma hegemonia internacional do capitalismo e da sociedade de consumo americana. As sociedades que não correspondessem a este ideal de "povo desenvolvido" teriam a legitimidade de suas opções políticas, econômicas e estilos de vida classificados como atrasados. A partir da década de 70 contrapondo essa ideia de desenvolvimento os movimentos culturais e os recentes movimentos ecológicos vão questionar o fracasso desse tipo de paradigma ora estabelecendo uma oposição radical ao ideário do consumo, ora incorporando à ideia de desenvolvimento uma dimensão ambiental que este projeto inicialmente excluíra de seu horizonte.

O termo "ecodesenvolvimento" surgir a partir dessa relação entre necessidade e limites do crescimento na conferencia de Estocolmo em 1972. Essa tentativa de equalizar os problemas ambientais dentro da lógica do capitalismo foi denominada de “capitalismo verde” por Dupuy. Logo, estes conceitos são antecessores do conceito de desenvolvimento sustentável. Com esse novo conceito, as questões ambientais são situadas no marco mais amplo das relações sociais, onde se reconhece a desigualdade entre os países e o aumento da pobreza como ameaças de um futuro social e ambiental equilibrado para todos. A difícil associação entre termos como econômico, social e ambiental estão representadas na relação conflituosa entre crescimento econômico, superação da pobreza e limites ambientais. Posto isto a autora aborda o processo em que a natureza passa de um "bem livre" sem valor econômico, dentro de uma visão clássica 
de desenvolvimento, para ser vista, dentro de uma perspectiva onde se insere o termo sustentável, como uma natureza com "capital”, onde os sujeitos e instituições que se apropriassem desse termo teriam um tipo de "capital ecológico". Sendo assim foi a partir da década de 90, principalmente com o acontecimento da conferência Eco-92, em que estes problemas sociais e ambientais tinham uma perene ligação, nascendo dai o termo "socioambiental". Um importante deslocamento que se dá nesse período é o de desenvolvimento sustentável para "sociedade sustentável" demarcando uma nova preocupação que é com a sustentabilidade da sociedade, mas do que com o desenvolvimento. Nessa reflexão o que está em jogo não é um sujeito nem uma prática: é um conceito. E como este conceito se articula com questões mais amplas da sociedade, fazendo com que falar sobre meio ambiente e desenvolvimento tenhamos inevitavelmente uma posição política.

\section{O "ambiental" em movimento e o movimento ambiental}

Ao refletirmos sobre um programa para uma disciplina de políticas ambientais outro eixo importante se refere à história dos movimentos ambientais. Pensar a partir de quais condições é possível o surgimento de movimento ambientais associado a uma transformação social e o modo de produção de políticas eficazes é a ideia de trabalho do livro "Ambientalismo e participação na contemporaneidade", detemo-nos aqui ao histórico que Lúcia da Costa Ferreira traz sobre o ambientalismo brasileiro nos anos de 1990 como uma crise e oportunidade de mudança social. Segundo a autora após a Rio92 o ambientalismo adentra a política e entra em nova crise: por uma pluralidade dos papeis sociais desempenhados pelos ambientalistas, caracterizando um movimento multisetorial e um certa crise de identidade ecológica. O nascimento desse novo movimento de caráter culturalista o centro é o sujeito e não as estruturas. É a autonomização da práxis política. Logo esse tipo de movimento começa a ter premissas generalizantes classificas como a dos movimentos sociais. Com atores diversificados a partir de ONGs os nacionalismos e regionalismos passaram a agir globalmente.

Um movimento importante para pensar esse processo na sua especificidade é movimento dos seringueiros. Em "A construção social de políticas públicas: Chico Mendes e o movimento dos seringueiros" Marly Allegretti reflete sobre esse movimento, que formulou uma política específica de reforma agrária e proteção 
ambiental, as Reservas Extrativistas, depois de mais de dez anos de confrontos em torno da terra e dos recursos naturais. Como resultado não se freio o desmatamento, mas, simultaneamente, cresceram os territórios protegidos, a maior parte deles em resposta ás demandas de povos e comunidades tradicionais. Esta relação entre reforma agraria e o movimento ambiental caracterizado como integrante dos "novos movimentos sociais" no que se refere ás análises das ações e identidades coletivas criadas no processo de formação do campo político - é dada a partir de aproximações e distanciamentos. Movimentos sociais aproximam-se dos movimentos ambientalistas, mas não fazem por uma concepção abstrata sobre natureza, e, sim, porque a utilizam como fator de produção e meio de vida. Conseguem com isso, aliar-se a entidades ecológicas sem ser uma delas. Através de uma luta contextualizada em um processo histórico os seringueiros, muito representados pela figura simbólica de Chico Mendes, criaram mecanismo de luta igualmente simbólico como o "empate". Nesse momento, o questionamento ao desmatamento não se dava por razões ambientais, mas por motivos sociais e econômicos, na medida em que dependiam para viver de uma floresta que estava sendo derrubada. A proposição de um novo modelo de desenvolvimento que associasse a proteção da floresta com benefícios econômicos e sociais para as populações teve consequências como assassinato de Chico Mendes, mas também refletiram na criação do Conselho Nacional dos Seringueiros (CNS) e de Reservas Extrativistas. A redefinição de objetivos da reforma agrária e da proteção ambiental abriu um campo conceitual novo que difere daquele encontrado na literatura onde a relação entre o social e o ambiental está associada aos impactos que a pobreza causa sobre o meio ambiente, mas do que ás contribuições que populações pobres poderiam dar para protegê-lo.

O conceito de "Justiça Ambiental" é outro que se inclui nesse processo de reflexão sobre políticas ambientais. Segundo Henri Acselrad, Selene Herculano e José Augusto Pádua tal processo nos instiga a entender que os índios florestais em Roraima, a seca do nordeste, a desigual exposição dos grupos sociais aos riscos da população são a expressão do mesmo processo de produção de "desigualdade ambiental" que distancia classes, raças e gêneros. Existe uma correlação entre pobreza, doenças associadas a falta de saneamento, produção de dejetos, privatização dos recursos ambientais coletivos. Como vimos antes à ideia de "risco" era vista como tendo o mesmo significado para o planeta. Agora este risco é dividido e potencializado nas minorias. Nesse sentido os 
sujeitos de direitos não são somente os humanos: amplia-se o leque de análise e, nesse sentido, a desigualdade social passa a ser um dos tipos de desigualdade ambiental. Esta relação entre sociedade e natureza reflete assimetrias sociais e econômicas, as quais são específicas de um determinado momento histórico e de uma configuração espacial. Essa separação entre sociedade e natureza, cultura e ambiente, não é inocente: é uma perspectiva política. Sendo assim este conceito questiona uma suposta neutralidade da natureza.

Na obra "Justiça Ambiental e Cidadania" os referidos autores contextualizam a Justiça Ambiental e as dinâmicas das lutas socioambientais no Brasil. Partindo da conferência da ONU sobre Meio Ambiente em 1972 e seus 26 princípios a centralidade era a natureza, pensar sobre a terra e os rios era o eixo das propostas. Sendo assim os países em desenvolvimento deveriam dirigir seus esforços para o desenvolvimento tendo presente as questões ambientais, ou seja, o imperativo do desenvolvimento e a ressalva ambiental. Nesse sentido não há sujeitos, só há a natureza. Contudo no EUA estava surgindo um movimento relacionado ao de justiça racial que se perguntava: o que se faz no meu quintal? As questões ambientais se inseriram na agenda destas discursões de tal movimento muito ligadas à territorialidade. Termos o de "racismo ambiental" surge dessa apropriação do discurso ecológico questionando fatos como a instalação de empresas em determinadas localidades agravavam a pobreza dos negros, pois embora a intenção não fosse racista, a consequência o era. Eis uma citação significativa para o entendimento do conceito:

\footnotetext{
Pensamos que o tema Justiça Ambiental - que indica trabalhar a questão do ambiente não apenas em termos de preservação, mas também de distribuição de justiça - representa o marco conceitual necessário para aproximar em uma mesma dinâmica de lutas populares pelos direitos sociais e humanos e pela qualidade coletiva de vida e a sustentabilidade ambiental. (Acselrad, Henri; Herculano, Selena; Pádua, José; 2004)
}

Nesse sentido, Justiça ambiental mais que expressão do campo do direito, assume-se como campo de reflexão, mobilizando a bandeira de luta de diversos sujeitos e entidades. É um conceito aglutinador e mobilizador, por integrar as dimensões ambiental, social e ética da sustentabilidade e do desenvolvimento, frequentemente dissociados nos discursos e nas práticas. 
Através da discussão de conceitos de desigualdade, justiça e racismo ambiental a questão dos "conflitos ambientais" aparece como uma ferramenta de análise para a reflexão de políticas nesse sentido. Conflito é uma categoria de produção e interesse sociológico. A identificação de um conflito não é uma posição neutra. Nesta perspectiva a um deslocamento de uma perspectiva em que diferentes sujeitos enxergam a mesma coisa através de posições distintas para outra perspectiva onde os sujeitos como indivíduos localizados veem nas suas diferenças pontos que não são iguais. Vários são os caminhos para pensar a ideia de conflito no campo sociológico: perspectivismo, póscolonialismo e multiculturalismo são escolas que se debruçam sobre o esta categoria e produzem abordagens distintas a respeito dela. Então no que diz respeito aos conflitos ambientais, ele envolve grupos com modos diferenciados de apropriação, uso e significado do território. Segundo Henri Acselrad (2004) em "as práticas espaciais e o campo dos conflitos ambientais", essa apropriação por parte dos grupos do território é técnica, social e cultural. Este tipo de conflito é uma problemática evolucionista, economicista e dos grupos com racionalidade não hegemônica. Enfim, outra ferramenta de análise desse conflito é a ligada ao plano material e ao plano simbólico. Materialmente se refere ao espaço físico, concreto sobre o qual se decorre o conflito. $\mathrm{Na}$ dimensão do simbólico, este conflito se dá na ecologização das ideias, no significado simbólico da dimensão da cultura.

\section{Saberes tradicionais e formação ambiental: as políticas ambientais no campo constituição dos sujeitos ecológicos}

Comunidades tradicionais e suas relações com a conservação ambiental têm sido uma questão importante nas políticas ambientais. De "entraves do desenvolvimento à linha da frente da modernidade estas populações passaram por um processo que as garantiu legitimidade no campo dos saberes tradicionais e da conservação. Mas o que são comunidades tradicionais? Essa é uma das perguntas que Manuela Carneiro da Cunha se faz em "Cultura com aspas e outros ensaios de antropologia”. Define tais comunidades de maneira extensional enumerando seus atuais e futuros membros. Esta abordagem está de acordo com a ênfase que dará à criação e à apropriação de categorias, e, o que é mais importante, ela aponta para a formação de sujeitos por meio de novas práticas. No momento, a expressão "populações tradicionais" ainda é uma 
categoria pouco habitada. Para começar tem existência administrativa: o Centro Nacional de Populações Tradicionais, um órgão do Ibama. Estes grupos estão dispostos a negociação de em troca do controle sobre o território, comprometem-se a prestar serviços ambientais. Dentro de um processo histórico de relacionamento positivo com organizações como a Associação Brasileira de Antropologia (ABA) e o Ministério Público estas populações tradicionais obtiveram resultados positivos que daria frutos na constituição de 1988. Os direitos sobre terras de populações tradicionais foram declarados como sendo "originários", um termo jurídico que implica a precedência e que limita o papel do estado a reconhecer esses direitos, mas não outorgá-los. Essa formulação tem a virtude de ligar os direitos territoriais às suas raízes históricas. Tal ideia reflete que as pessoas mais qualificadas para fazer a conservação do território são as pessoas que nele vivem sustentavelmente e na luta por institucionalização de territórios para estas populações essa é a premissa de um novo conceito surgirá: reservas extrativistas. No Brasil uma política ecológica sólida e viável deve incluir populações locais. Além disso, expulsar pessoas das áreas de preservação sem lhes oferecer meios alternativos de subsistência é rota segura para desastres.

Refletindo sobre essa ligação ente populações locais e áreas protegidas Rosane Manhães Prado traz o caso específico do território de Ilha Grande/RJ. A autora se inspira em colocações de Ingold e kurttila (2000) a partir da forma de abordagem e de entendimento que propõem para a noção de conhecimento tradicional local. Estes autores além de proporem que se dissolva a separação entre ciências naturais e sociais, privilegiam os aspectos de movimento e processo por oposição aos programas, lógicas ou gramáticas vistos como subjacentes aos fatos observados. É nessa perspectiva estes autores tem quando falam do conhecimento que as pessoas têm dos seus ambientes e de como nele se inserem:

Tratam-se de conhecimentos que não são do tipo formais e autorizados, transmissíveis em contextos fora de sua aplicação prática. Ao contrario, são baseados em sentimentos, consistindo de habilidades, sensibilidades e orientações desenvolvidas através de longas experiências de condução da própria vida num ambiente particular. (Ingold e Kurttila, 2000)

Cabe reconhecer que esta discussão conceitual sobre categorias como tradição e cultura guarda uma correlação direta com a problemática da criação e manutenção das chamadas áreas ambientais protegidas, ou unidades de conservação ambiental. Contraria 
a uma visão mecânica de populações tradicionais questiona: ser ou não ser tradicional da perspectiva de que está falando? Quem, e por que, está preocupado com isso? É preciso reconhecer que estamos diante de visões de dentro e de fora destas populações, e de uma cobrança de fora para dentro destas populações - no caso de estudo a do Aventureiro - que seguem sendo como são e vivendo como vivem.

Outro eixo possível de ser discutido são os das Populações Rurais e sua relação com Políticas Ambientais. Os casos das construções de hidrelétricas e barragens são representativos da questão de como experiências locais e olhares globais se articulam. Nesse sentido Andréa Zhouri através de uma reflexão sobre o Vale do Jequitinhonha aborda conceitos como o de desenvolvimento sustentável e como este tem ligação com a construção de consenso global sobre o ambiente. Através do paradigma da adequação ambiental o meio ambiente é visto como algo externo que precisa ser adaptado às técnicas de desenvolvimento. Reflete sobre as visões diferentes dos construtores de laudos técnicos de projetos ambientais em que a natureza é desencarnada e vista como algo a parte e a visão dos atingidos por estes laudos em que a natureza é entendida como algo cotidiano presente na rotina das suas vidas. Sendo assim pensar o sujeito e o mundo desde o mesmo lugar, a paisagem e o indivíduo do mesmo espaço físico e simbólico, é parte de uma percepção em que há uma articulação entre o mundo e o sujeito, pois não se pode falar do sujeito sem falar da paisagem, e a recíproca é verdadeira. Pensar nesses sujeitos através de suas experiências e das relações de poder que o permeiam é uma saída conceitual e política para entender indivíduo e ambiente sem serem coisas diferentes, pois esse modo de distinção tem capacidade de proposta política.

Tratando-se de Educação Ambiental segundo Isabel Carvalho em "Educação, cidadania e justiça ambiental: a luta pelo direito da existência" do ponto de vista de sua dimensão político-pedagógica, poderia ser determinada como uma educação crítica voltada para a cidadania. Ela produz/articula pedagogicamente conflitos que também produzem relações, que podem ser ponto de partida para a tematização ecológica. $\mathrm{O}$ motivo central destes conflitos é a tensão entre o caráter público dos bens ambientais e sua disputa por interesses privados. Em todas as formas de manifestações, fica claro que a reivindicação tem como objeto o caráter público do meio ambiente. O interesse privado de bens ambientais além de ocasionarem agressões ambientais, fere seu caráter 
coletivo. Essa consciência de riscos compartilhados pode atuar como força agregadora, cooperando para formação de redes de ações solidárias.

Essa educação ambiental também é abrangida por uma dimensão imediatista e propositiva ligada a "mudanças de comportamento" frente ao meio ambiente; e outra dimensão mais educativa e analítica relacionada a uma perspectiva abrangente e orgânica que visa resultados em longo prazo como a transformação de um ideal da sociedade frente à natureza visando "formação de atitudes". A educação ambiental é transversal e interdisciplinar quando pensa a prática educativa: vai além de uma questão explicitamente ecológica. Nesse sentido uma dimensão filosófica ligada à educação ambiental se relaciona com Hans Jonas (2004) quando é abordada a questão da razão instrumental.

\begin{abstract}
A convivência entre humanos e ambiente tem sido marcada pelo domínio de uma racionalidade instrumental e utilitária, em detrimento a uma postura de reciprocidade ante a natureza enquanto alteridade a ser respeitada entendendo-a não só como as formações florestais, os mananciais e outros ecossistemas remanescentes, por exemplo, mas também como uma base natural dos ambientes da vida social, ou seja, a base natural do nosso dia-a-dia. (Jonas, Hans; 2004)
\end{abstract}

Uma análise sobre a teia emaranhada atores presentes nessa relação de sociedade/natureza, como de grupos sociais no campo e na cidade, se percebe a luta por legitimarem formas de uso dos bens ambientais, de acesso a eles e de convivência e interação com o ambiente, assim como os saberes correspondentes. $\mathrm{O}$ caso da luta em que ribeirinhos liderados por padres franciscanos denunciam o desmatamento nos vales do rio São Francisco testemunha uma das composições possíveis entre ideários diversos, como o religioso-popular e o ecológico, em que ambos os universos se entrelaçam e, ao mesmo tempo, se recriam mutuamente. Exemplo de como as lutas populares emancipatórias podem ser elementos-chave na construção de uma cidadania ambiental, estabelecendo um campo de dialogo entre as reivindicações ambientais e as demandas populares.

A constituição de um sujeito ecológico pode ser relacionada a um novo modo de fazer política através da natureza. Bruno Latour em "Políticas da Natureza" reflete sobre a mediação humana para com direitos não humanos. Quem vai falar em nome da natureza quando esta, sem as capacidades de fazer políticas por si só, tem necessidade de quem algum sujeito humano a represente no fazer político? Sabemos que o micoleão-dourado não pode ir ao parlamento nem os rios podem se autodefender no caráter 
político. Estas políticas onde a natureza possa emergir no espaço da política como um sujeito de direitos partem da perspectiva que toda a ação sobre a natureza é uma ação que produz uma relação onde esse sujeito da natureza tem agencia. A mediação humana seria uma representação social que se estabelece na necessidade de ouvir estes sujeitos e falar em nome deles.

Mas quem é este sujeito ecológico que estabelece essa mediação representativa? É essa a questão que Isabel Carvalho reflete em "A invenção do sujeito ecológico". A partir do aporte teórico de cinco referências de estudo sobre o assunto a autora conclui destes estudos que o sujeito ecológico tem múltiplas faces. Não há um manual de como fazer ecologia estabelecendo-se assim uma pluralidade das praticas destes novos sujeitos. A educação ambiental é a ação educativa destes sujeitos que são educadores ambientais categorizados em gerações e contextualizados num processo histórico nacional de inserção da temática ambiental na sociedade civil. A construção de um ambiente histórico de um campo ambiental relaciona a emergência desses novos atores com a visibilidade da questão ambiental decorrentes de um contexto de guerra fria e de movimento de contracultura. Esse "ecologismo contracultural" criticou um modelo desenvolvimento consumista americano e o estilo de vida da esfera pública, promovendo um ideário emancipatório e fundador da história política do movimento ambiental. Logo a "militância" é um sinal distintivo e positivo no sentido de ser menos atrelada a organizações ideológico-partidárias e mais voltada a ideias e princípios. Nesse sentido há uma debate entre um "romantismo" associado a paixão e a militância e um "racionalismo" associado a uma profissionalização.

A religião aparece aqui como umas dos fenômenos sociais que se apropria do discurso ecológico na formação destes agentes e a este processo dá-se o nome de sacralização da natureza. De outro modo a natureza também é vista é como algo religioso que se apropria de um ideário de naturalização do sagrado. Rodrigo Toniol ao pesquisar as caminhadas na natureza por um grupo de ecoturistas no Paraná pensa a questão "bem estar" para além do corpo e do ambiente físico. A natureza surge como um fluxo energético onde não se pensa somente o conteúdo da caminhada, mas a ação de caminhar. Os ecologistas são atravessados por uma serie de sentidos e um deles é o sentimento religioso ligado às novas consciências religiosas ou a New Age. Essa subjetividade que relaciona cristianismo e ecologia se conecta com a luta pela Justiça Ambiental e da visão da natureza como portadoras de direitos associada uma 
“cosmovisão ecológica”. Então a uma porosidade no campo ambiental de racionalidade inclusiva ligada uma fronteira entre o espiritual e o científico onde os sentidos transitam, mas não se excluem.

Para finalizar não poderia deixar de mencionar Tim Ingold como um teórico importante no que se refere ao debate das questões ecológicas não só na antropologia, mas como nas diversas disciplinas em busca permanente pelos "padrões que unem" (Bateson, 1987). Ingold propõe uma "Antropologia Vitalista" que leve em consideração a vida e que não se esgota na representação, que seja mais que representacional. Se afastando da ideia de ontologia e do perspectivismo - principalmente relacionada a Descola e Viveiros de Castro - a autor refrete que habitamos o mesmo mundo (monismo) de formas distintas. Através de uma ideia Deleuziana de "devir" que se reflete a procedência dos processos frente as formas Ingold se utiliza do conceito de ontogênese. $O$ fato de habitarmos o mesmo não quer dizer que ele não seja plural nas suas formas de habitar.

Em 2000 Tim Ingold lançou "The perception of the environment: essays on livelihood, dwelling and skill" numa tentativa de romper com a disciplinaridades entre Antropologia, Biologia, Educação e Psicologia. Já em 2013 lança "Making” tentando aproximar agora a Antropologia, Arqueologia, Artes e Arquitetura. Como isso se associa a ideia de sociedade? Ingold traz algumas pistas para este entendimento em "Trazendo as coisas de volta à vida: emaranhados criativos num mundo de materiais" (2012) onde constrói o texto pensando numa crítica as ideias laturianas de sociedade. Uma primeira categoria que o autor questiona é a de "objeto" em contraste com a “coisa". Um objeto estaria no plano do fato consumado, já as coisas seriam "fios vitais em um lugar onde vários aconteceres se entrelaçam" (Ingold, 2012). Objetos são colocados em contraste com o mundo, pois tem exterioridade. Já as coisas são o que fazem a vida acontecer, pois atuam num processo de "coisificação" no qual devemos nos juntar a ele, num fluxo contínuo de um acontecer:

Se pensarmos cada participante como seguindo um modo de vida particular, tecendo um fio através do mundo, então talvez possamos definir q coisa como um parlamento de fios. (Ingold, 2012) 
Neste parlamento de fios não existe contraste com o mundo, a coisa não tem exterioridade, nem um fechamento em si. Ela é uma superfície em fluxo no qual não olhamos, nos juntamos aos movimentos dos fluxos. Outra questão interessante são as diferenças entre "agência" e "vida". O grande problema da ideia de agência é que ela quer "embutir a vida" em algo que já a tem. A vida é um habitar o mundo em um ambiente sem objetos. Não há nada que seja contínuo em si mesmo, por isso as coisas vazam. Assim tudo está em movimento, mesmo que não pareça.

Da sociedade para o mundo Ingold considera significativa a distinção entre linhas de conexão da rede e as linhas de fluxo da malha. A primeira é mapeada por objetos e agências com limites interiores e exteriores. A segunda é são fluxos e contrafluxos, serpenteando, através ou entre, sem começo nem fim. Na primeira as relações são "entre" objetos, na segunda são "ao longo" de malhas, linhas e fluxos de vida. Por fim a primeira, a da teoria do ator-rede é repleta de materialidades acabadas, enquanto a malha é vazada por materiais tendo por base a etneração dos modos de seguir no mundo.

\section{Referências}

ACSELRAD, Henri; SILVA, Maria das Graças da. Conflitos Ambientais no Brasil. Rio de Janeiro: Relume Dumará, 2004.

ACSELRAD, Henri.; HERCULANO, Selena; Pádua, José. Justiça ambiental e cidadania. Rio de Janeiro: Relume Dumará, 2004.

ALLEGRETTI, Mary. A construção social de políticas públicas. Chico Mendes e o movimento dos seringueiros. Desenvolvimento e Meio Ambiente, n. 18, p. 39-59, jul./dez. 2008. Editora UFPR.

BATESON, George. Steps to an ecology of mind. Collected essays in anthropology, psychiatry, evolution and epistemology. Jason Aronson Inc. New Jersey, 1987.

BARRETTO FILHO, H. T. Notas para uma História Social das Áreas de Proteção Integral no Brasil. In: Fany Ricardo. (Org.). Terras Indígenas e Unidades de Conservação da Natureza: o desafio das sobreposições. São Paulo: Instituto Socioambiental, 2004

CARNEIRO DA CUNHA, Manuela e Almeida, Mauro. Populações tradicionais e conservação ambiental. In: Cultura com Aspas. São Paulo, Cosac Naify. 2009, p. 277 a 300.

CARVALHO, Isabel C. M. Educação Ambiental: a formação do sujeito ecológico. 5a. Ed. 2010.

CARVALHO, Isabel C. M. A política em trânsito e os trânsitos na política. In: $A$ Invenção Ecológica. [2001] 2008, 3a. Edição, Porto Alegre: Editora da UFRGS.

Debate sobre $\mathrm{O}$ futuro que queremos. A conferência da ONU sobre meio ambiente e os eventos da Rio +20

FERREIRA, Lucia da Costa. Ambientalismo brasileiro nos anos 90: crise e oportunidade de mudança social. In: Sorrentino, Marcos. Ambientalismo e participação na contemporaneidade. São Paulo: Educ, 2002.

INGOLD, Tim. Trazendo as coisas de volta à vida: emaranhados criativos num mundo de materiais. Horizontes Antropológicos, v.18, n.37, 2012.

INGOLD, Tim. Lines: a brief history. Routledge, 2007. 
INGOLD, Tim. Making: Anthropology, Archaeology, Art and Architecture. 2013.

INGOLD, Tim. The Perception of the Environment: Essays on Livelihood, Dwelling and Skill, 2000.

JONAS, Hans $O$ princípio da responsabilidade. Editores Contraponto e PUC-Rio, Rio de Janeiro, 2005. (p. 89 a 93)

LATOUR, Bruno. "Por que a ecologia da política não saberia conservar a Natureza?". In:

Políticas da natureza: como fazer ciência na democracia. Bauru, SP: EDUSC, 2004, pp. $\overline{25}-$ 95.

PRADO, Rosane Manhães, Viagem pelo conceito de populações tradicionais, com aspas. In: Steil, Carlos Alberto e Carvalho, Isabel Cristina de Moura. Cultura, Percepção e Ambiente. São Paulo: Terceiro Nome, 2012, p. 173 - 189.

SCOTTO, Gabriela; CARVALHO, Isabel; GUIMARÃES, Leandro. Desenvolvimento Sustentável: a história de um conceito. In: __ Desenvolvimento Sustentável. [2007] 2011, 6a. Edição, Petrópolis: Vozes.

SILVA, Gláucia. Angra I e a melancolia de uma era. Um estudo sobre a construção social do risco. Niterói: Editora da UFF, 1999. v. 1. 284

SILVA, Telma Camargo da. XXII Encontro Anual da ANPOCS. Corpos em perigo: uma análise sobre percepção de risco em caso de desastre radiológico. 1998 (mimeo).

TONIOL, Rodrigo; STEIL, Carlos Alberto. O idioma ambiental e a promoção de caminhadas na natureza: etnografia de uma política de turismo rural no Vale do Ivaí, Paraná. Revista Paranaense de Desenvolvimento.

ZHOURI, Andréa; Oliveira, Raquel. Experiências locais e olhares globais. Desafios para os moradores do Vale do Jequitinhonha - MG no campo ambiental. In: Steil, Carlos Alberto e Carvalho, Isabel Cristina de Moura. Cultura, Percepção e Ambiente. São Paulo: Terceiro Nome, 2012, p. $191-209$.

Recebido em: 26/10/2015. Aprovado em: 06/04/2016. 